\title{
The Electrical Properties of SBR-NBR Interlinked Composites Loaded with Metal Salts
}

\author{
M. Abu-Abdeen, GM. Nasr, H.M. Osman and A.I. Aboud \\ Physics Department, Faculty of Science, Cairo University, Giza, Egypt.
}

Different concentrations of fillers $\mathrm{CoO}$ and $\mathrm{Ni}(\mathrm{OH})_{2}$ were incorporated in SBR-NBR interlinked composites. The dc electrical conductivity, $\sigma_{d c}$, for such composites were measured. The results of the dc conductivity were compared with samples containing HAF carbon black. The temperature dependence of the dc conductivity was also measured. The activation energy calculated was found to be highly affected by both the type and concentration of the filler. The dielectric properties namely; dielectric constant, $\varepsilon$, dielectric loss, $\varepsilon^{\prime \prime}$, and the ac electrical conductivity $\sigma_{a c}$ were measured as functions of both frequency and concentration of the filler. The results were analyzed according to an equivalent circuit model. 


\section{Introduction:}

Measurements of the electrical properties of polymers are one of the most convenient and sensitive methods for studying polymer structure. A filled polymer differs substantially from the free one in a wide range of properties. The presence of filler affects both the electrical, as well as, mechanical properties [1-3]. In most of their industrial applications, elastomers are used as composite materials. The incorporation of fillers into rubbery polymers imparts many interesting and useful properties to the particle filled composite materials [4-6].

It has been established that the electrical conductivity of such composites depends on the type and concentration of the filler used $[7,8]$. When carbon black is used as filler, the conductivity of the composite is increased, coupled with a high degree of improvement in mechanical strength. However, when metal powders are used, high conductivity can be achieved but the system lacks high mechanical strength [7]. It is also found that the extent of improvement in both mechanical and electrical properties of filled composites is a function of filler loading.

The ability of fillers to interact physically and/or chemically with elastomers is an important aspect of reinforcement. However the measurements of filler-polymer interaction has often been difficult because of the problem of isolating this parameter from other physical and chemical phenomena, e.g. the polymer crosslink-network, filler microdispersion and polymer occluded within the filler structure.

The physical properties; (such as the strength of adhesion) of interlinked composite (two elastomer layers vulcanized in contact) are important for practical applications [9-11]. Composite performance is directly correlated to its properties at the interface. The exact relationship, however, is not clearly understood. The analysis is complicated by the fact that other factors such as the geometrical parameters of fillers, the vulcanization conditions and the vulcanizing agents have great influence on the physical properties. Computer simulation in conjunction with filler fragmentation data has shown that filler surface treatment can affect stress propagation ability at interface [12]. Other studies have shown that improvements in the bonding properties yielded very limited improvements in the composites $[13,14]$.

As a continuation of a previous work [15], the present study is done to investigate the effect of both $\mathrm{CoO}$ and $\mathrm{Ni}(\mathrm{OH})_{2}$ as fillers on the dc and ac conductivities as well as the dielectric properties. 


\section{Experimental:}

\section{Materials used and sample preparation technique:}

A master batch of Styrene-butadiene rubber (SBR) was prepared and then loaded with different concentrations of cobalt oxide $(\mathrm{CoO})$ and nickel hydroxide $\left[\mathrm{Ni}(\mathrm{OH})_{2}\right]$. Also a master batch of nitrile-butadiene rubber (NBR) was prepared without fillers. All samples were prepared according to the recipe presented in Table (1).

Table (1): Mix formation of SBR-NBR interlinked samples loaded with $\mathrm{CoO}$ and $\mathrm{Ni}(\mathrm{OH})_{2}$.

\begin{tabular}{|l|c|c|c|}
\hline Ingredient (phr) & \multicolumn{3}{|c|}{ Concentration (phr) } \\
\hline SBR & 100 & 100 & --- \\
\hline NBR & --- & --- & 100 \\
\hline $\mathrm{CoO}$ & $1,2,3,5,10,20$ & --- & --- \\
\hline $\mathrm{Ni}(\mathrm{OH})_{2}$ & --- & $1,3,5,10,20$ & --- \\
\hline Processing oil & 10 & 10 & 10 \\
\hline Stearic acid & 2 & 2 & 2 \\
\hline MBTS $^{(\text {(a) }}$ & 2 & 2 & 2 \\
\hline PBN $^{(b)}$ & 1 & 1 & 1 \\
\hline Zinc oxide & 5 & 5 & 5 \\
\hline Sulfur & 2 & 2 & 2 \\
\hline
\end{tabular}

${ }^{\text {(a) Dibenthiazole, }}$

(b) Phenyl-napthylamine.

The compounds were mixed according to the ASTM D 3182 method in a laboratory-sized mixing mill at a fraction ratio $1: 1.19$, by carefully controlling the mixing temperature $\left(60-70{ }^{\circ} \mathrm{C}\right)$, nip gap $(1.5 \mathrm{~mm})$, time of mixing $(30 \mathrm{~min})$ and uniform cutting operation.

After mixing, the elastomers (SBR with different fillers and pure NBR) were put in contact [15] in a mold in an electrically heated hydraulic press to the optimum cure using molding conditions that were previously determined from torque data using a Monsanto rheometer R100 (a full description of samples interlinking and vulcanization is found in a previous work) to get the SBR-NBR interlinked composites.

\section{Electrical Measurements:}

The samples employed for electrical measurements were circular discs, which were sandwiched between brass plates. One electrode is insulated with teflon. The temperature of an electric oven was automatically controlled up to $140^{\circ} \mathrm{C}$. 
For the $\mathrm{dc}$ conductivity measurements, the dc current measuring equipment comprised a digital electrometer type 616 Kiethly. Using coaxial cables, metal shielding, and a common ground loop eliminated the electrical noise.

The dielectric properties were measured using a bridge type Philips PM 6304 programmable automatic RLC meter in the frequency range $10^{2}-10^{5} \mathrm{~Hz}$ and both the capacitance and $\tan \delta$ values were measured at $300 \mathrm{~K}$. The real part of the dielectric constant $\left(\varepsilon^{\prime}\right)$ was calculated from

$$
\varepsilon^{\prime}=11.3 \frac{\mathrm{d}}{\mathrm{A}} \mathrm{C}
$$

where $\mathrm{d}(\mathrm{cm})$ is the thickness of the sample, $\mathrm{A}\left(\mathrm{cm}^{2}\right)$ is the area and $\mathrm{C}(\mathrm{pF})$ is the capacitance. The imaginary part of the dielectric constant $\varepsilon$ ' was calculated from

$$
\varepsilon^{\prime \prime}=\varepsilon^{\prime} \tan \delta
$$

and the ac conductivity was calculated from

$$
\sigma=\omega \varepsilon^{\prime \prime} \varepsilon_{0}=2 \pi \mathrm{f} \varepsilon^{\prime \prime} \varepsilon_{0}
$$

where $\mathrm{f}(\mathrm{Hz})$ is the frequency.

\section{Results and Discussion:}

\section{The dc conductivity:}

Figure (1) shows the effect of fillers [ $\mathrm{CoO}$ and $\left.\mathrm{Ni}(\mathrm{OH})_{2}\right]$ loading on the $\mathrm{dc}$ conductivity of interlinked systems. It is observed that as the quantity of filler is low ( $<5 \mathrm{phr}$ for both fillers) the conductivity of the interlinked system has a sharp increase. Beyond this filler loading the increase in conductivity is relatively small. The curves in Figure (1) are well fitted with an empirical equation of the form

$$
\sigma_{\mathrm{dc}}=\sigma_{\mathrm{o}} \sinh (\alpha \mathrm{C})
$$

with $\sigma_{o}$ and $\alpha$ are fitting parameters with values $7 \times 10^{-13}\left(\Omega^{-1} \mathrm{~cm}^{-1}\right), 0.04$ and $1.5 \times 10^{-12}\left(\Omega^{-1} \mathrm{~cm}^{-1}\right)$ and 0.01 for $\mathrm{CoO}$ and $\mathrm{Ni}(\mathrm{OH})_{2}$, respectively.

The theory based on non-Ohmic conduction in the system [16] is found to be true only at very low concentrations of conductive additives $(\leq 30 \mathrm{phr})$ in insulating matrix. Microbrownian motion of the rubber chains in the flexible rubber matrix may momentarily give rise to bridging of the small filler particles, bringing them close enough for electron tunneling to occur. The final equation based on this theory has the form [16].:

$$
\sigma_{\mathrm{dc}}=\sigma_{0} \exp \left[\mathrm{K}\left(\mathrm{V}_{\mathrm{f}}\right)^{1 / 3}\right]
$$




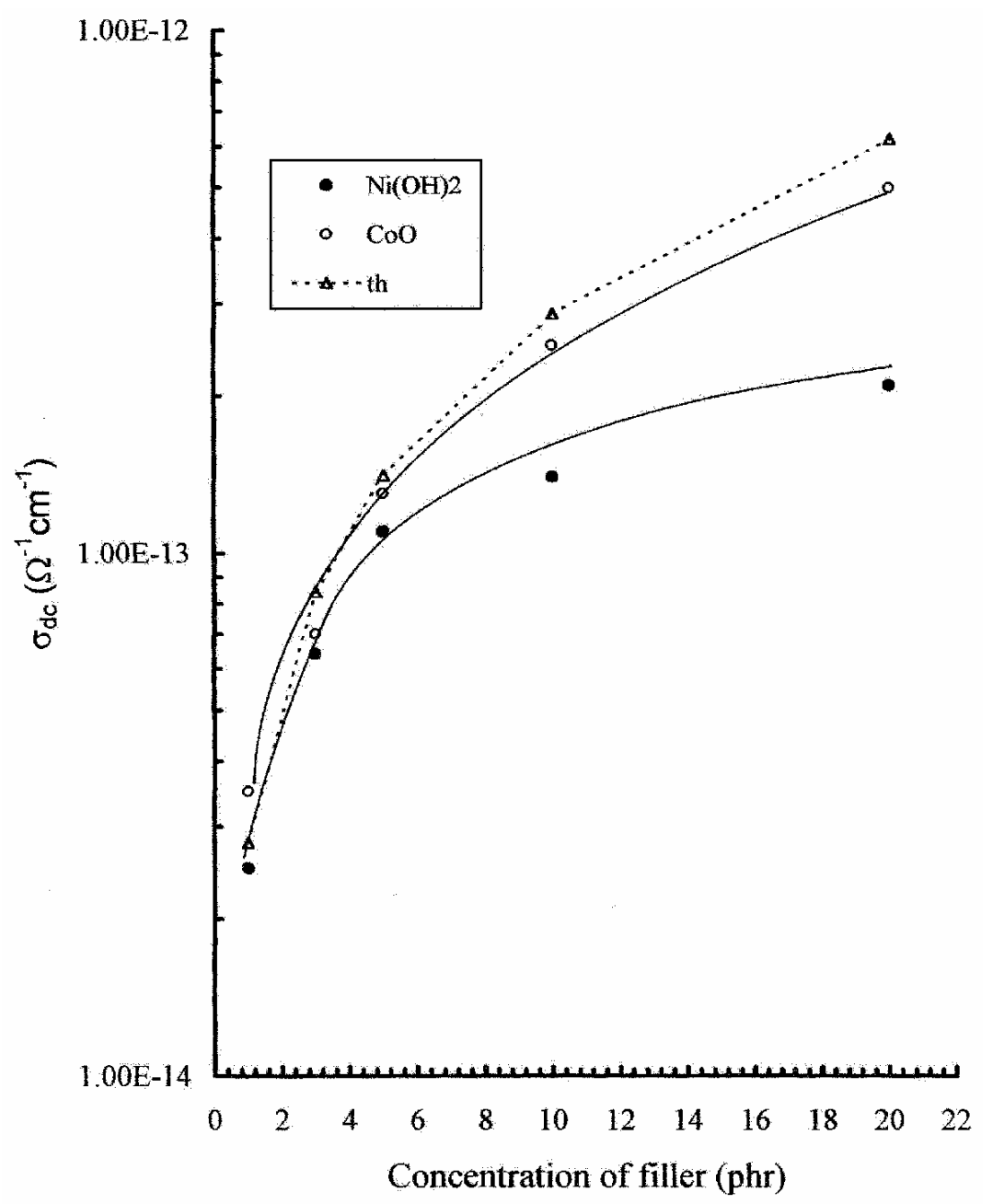

Fig. (1): The dependence of the dc conductivity on the concentration of the fillers.

where $\sigma_{\mathrm{dc}}$ is the conductivity of the system and $\sigma_{\mathrm{o}}$ is the conductivity at zero loading and $\mathrm{V}_{\mathrm{f}}$ is the volume fraction of filler in the interlinked system. According to equation (5) a plot of $\ln \sigma_{\mathrm{dc}}$ versus $\left(\mathrm{V}_{\mathrm{f}}\right)^{1 / 3}$ should yield a straight line; the corresponding plots for $\mathrm{Ni}(\mathrm{OH})_{2}$ and $\mathrm{CoO}$ loaded interlinked samples are shown in Figure (2). Good agreement between theoretical and practical values is obtained with $\sigma_{\mathrm{o}}=9.57 \times 10^{-15}, 7.53 \times 10^{-15}\left(\Omega^{-1} \mathrm{~cm}^{-1}\right)$ and $\mathrm{K}=11.05$ and $14.64 \mathrm{~cm}^{-1}$ for $\mathrm{CoO}$ and $\mathrm{Ni}(\mathrm{OH})_{2}$ respectively. This implies that conduction through electron emission mechanism predominates in the concentration range from 5 to $20 \mathrm{phr}$ of $\mathrm{CoO}$ meanwhile the conduction through electron tunneling predominates in the concentration range from 1 to $5 \mathrm{phr}$ of same filler. 


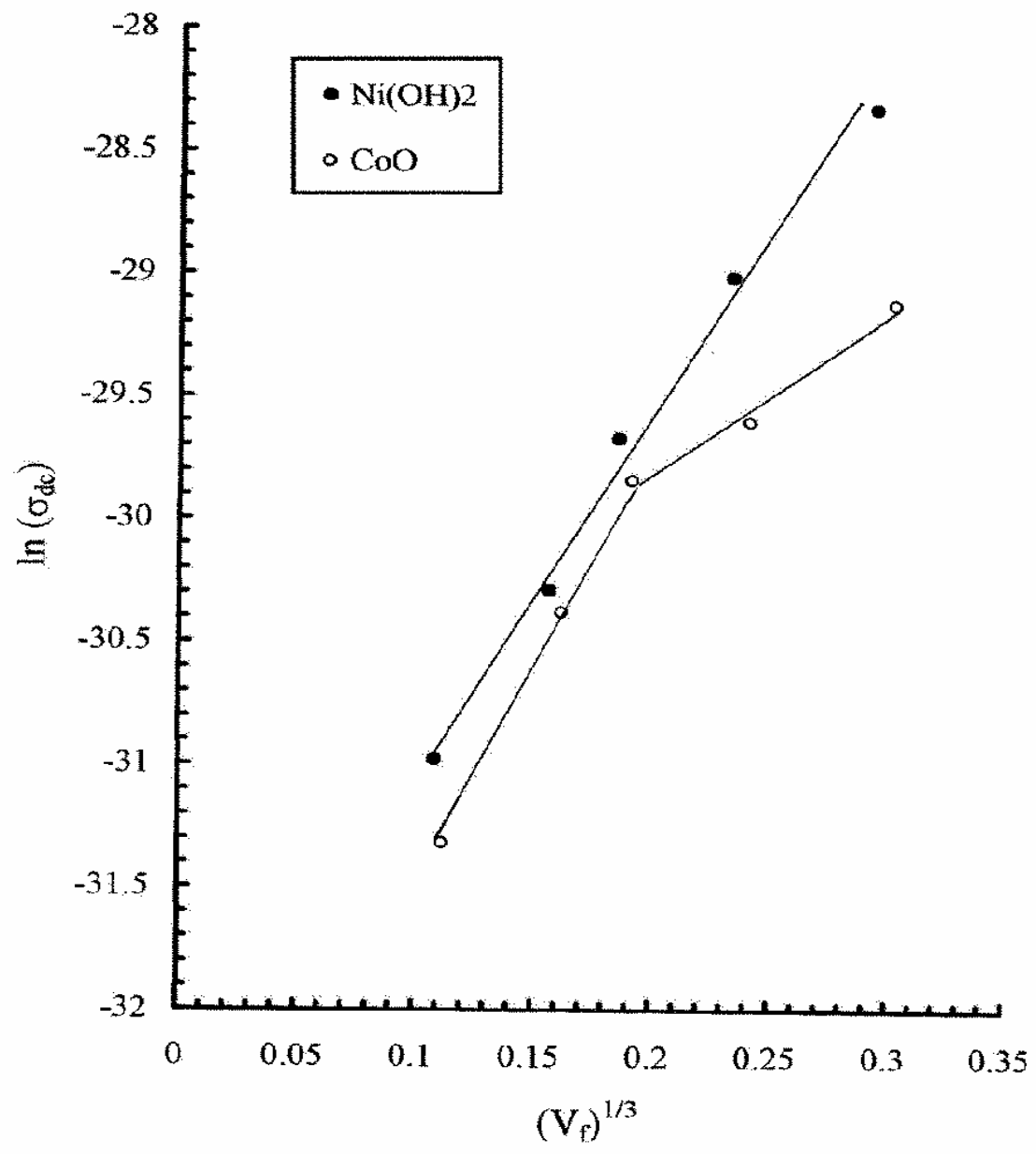

Fig. (2): The dependence of $\ln \left(\sigma_{d c}\right)$ on $V_{f}^{1 / 3}$ for all studied composites.

\section{Temperature dependence of dc conductivity:}

Tunneling is a quantum mechanical process in which the wave function of the electron is not confined entirely within the potential box, but has a small tail extending beyond the potential barrier $[17,18]$. Consider a stream of electrons of kinetic energy less than the potential barrier. Because of the tail, a very small fraction [17] (typically $10^{-5}$ to $10^{-10}$ ) of the electrons will penetrate the barrier and reach the adjacent aggregate of the filler. This process is dominant at ultra low temperatures (e.g., 1-100K, depending on the composition). Another mechanism, which in fact may be the dominant mechanism, in the case of low loading of filler at ordinary temperatures (room temperature and above); namely, the thermally activated transport of electrons 
over the potential barrier (hopping) may take place. At relatively low voltage both mechanisms follow Ohm's law. If the gap distance between the filler particles is greater than $10 \mathrm{~nm}$, the conduction mechanism is the same mechanism as in the absence of filler (i.e. transport by ionic impurities, space charge,.. etc).

Figures (3 and 4) depict the temperature dependence of the electrical conductivity of the NBR-SBR interlinked system loaded with $\mathrm{CoO}$ and/or $\mathrm{Ni}(\mathrm{OH})_{2}$, respectively. A three stage-behavior with different slopes is distinguished for all $\mathrm{CoO}$ and $\mathrm{Ni}(\mathrm{OH})_{2}$ loadings. The activation energies of the three stages are tabulated in Table (2). Using the Arrhenious equation

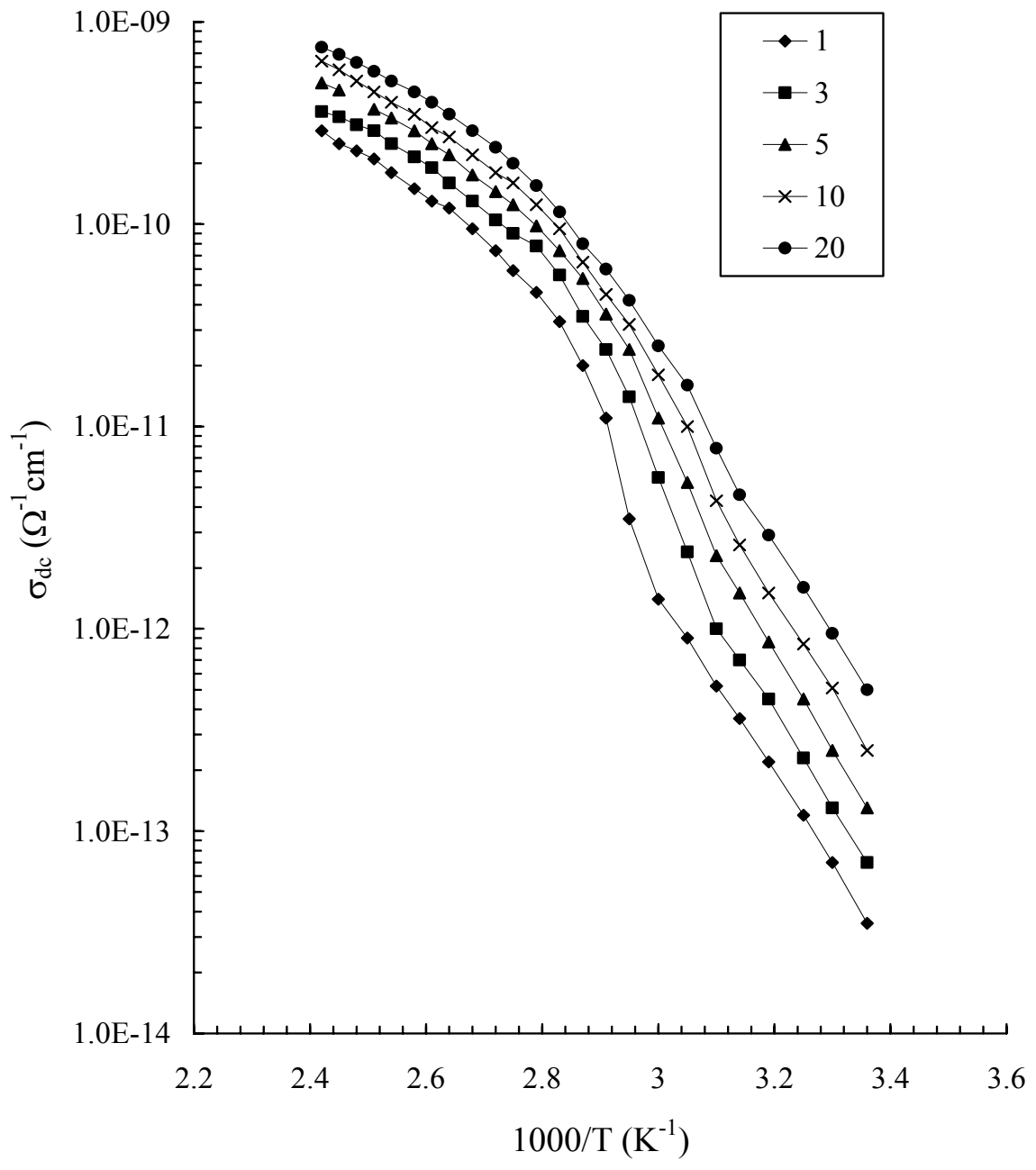

Fig. (3): The temperature dependence of the dc conductivity for composites loaded with $\mathrm{CoO}$. 


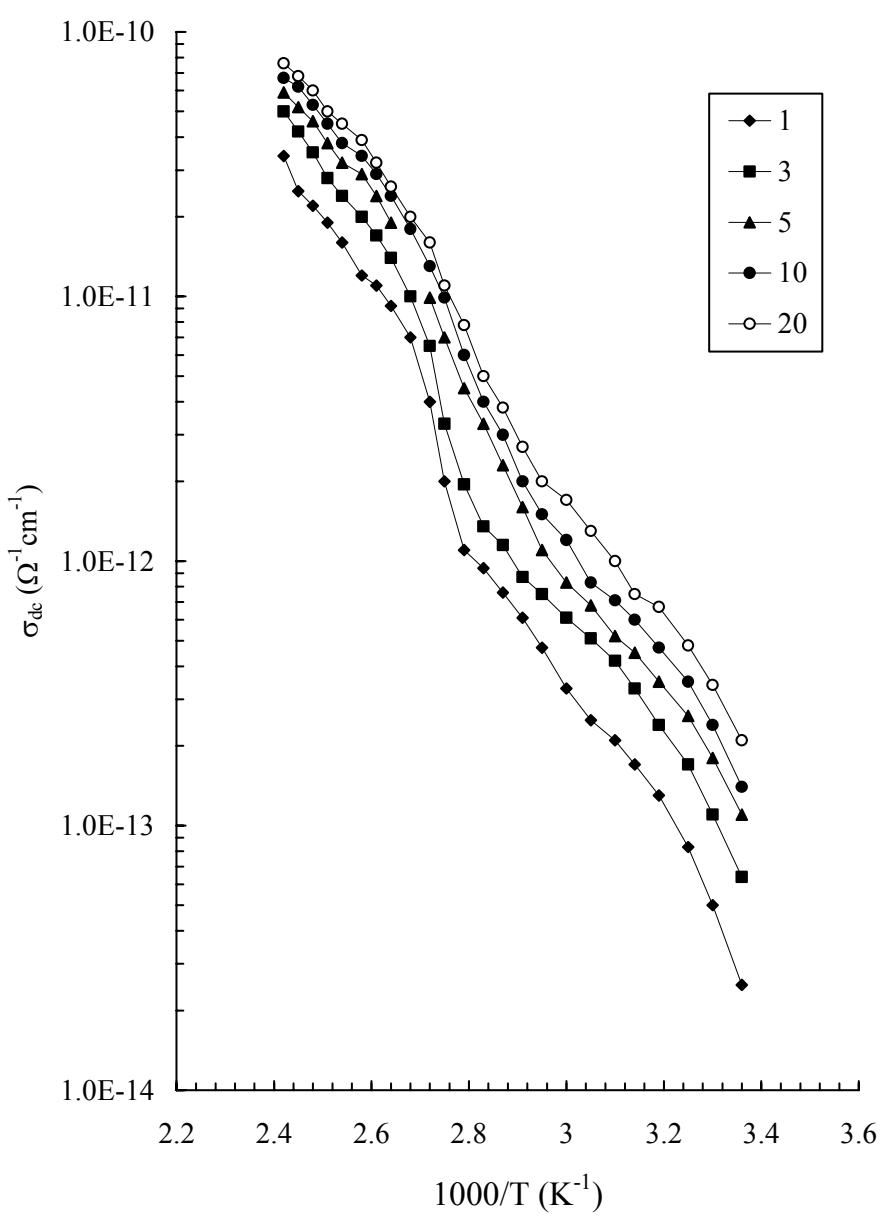

Fig. (4): The temperature dependence of the dc conductivity for composites loaded with $\mathrm{Ni}(\mathrm{OH})_{2}$.

$$
\sigma_{\mathrm{dc}}=\sigma_{\mathrm{o}} \exp \left[-\frac{\mathrm{E}}{\mathrm{k}}\left(\frac{1}{\mathrm{~T}}-\frac{1}{\mathrm{~T}_{\mathrm{o}}}\right)\right]
$$

which governs the $\log \sigma_{\mathrm{dc}}$ against $1000 / \mathrm{T}\left(\mathrm{K}^{-1}\right)$ relations, where $\sigma_{\mathrm{dc}}$ and $\sigma_{\mathrm{o}}{ }^{\prime}$ are the conductivities at temperatures $T$ and $T_{o}$ respectively, $k$ is the Boltzmann constant and $\mathrm{E}$ is the corresponding activation energy that listed in Table (2). It is observed from the table that the activation energy $\mathrm{E}$ decreases gradually with the $\mathrm{Ni}(\mathrm{OH})_{2}$ content for the three different regions. The same behavior is also detected for the $\mathrm{CoO}$ in the second region while, there is no detectable change in the activation energy for the $\mathrm{CoO}$ in the other two regions. 
It is obvious from Figures (5 and 6) that, the same loading (10 and/or 20 phr) of either the two fillers used and the HAF (High Abrasion Furnace) carbon black filler has different contributions to the dc conductivity. The $\mathrm{CoO}$ as filler aggregates leads to higher conductivity levels and three parts in the $\sigma_{\mathrm{dc}}-1000 / \mathrm{T}$ graph are distinguished. Meanwhile, the worse one is the HAF black. This may imply that $\mathrm{CoO}$ has a more reinforcing effect to the SBR matrix than HAF black.

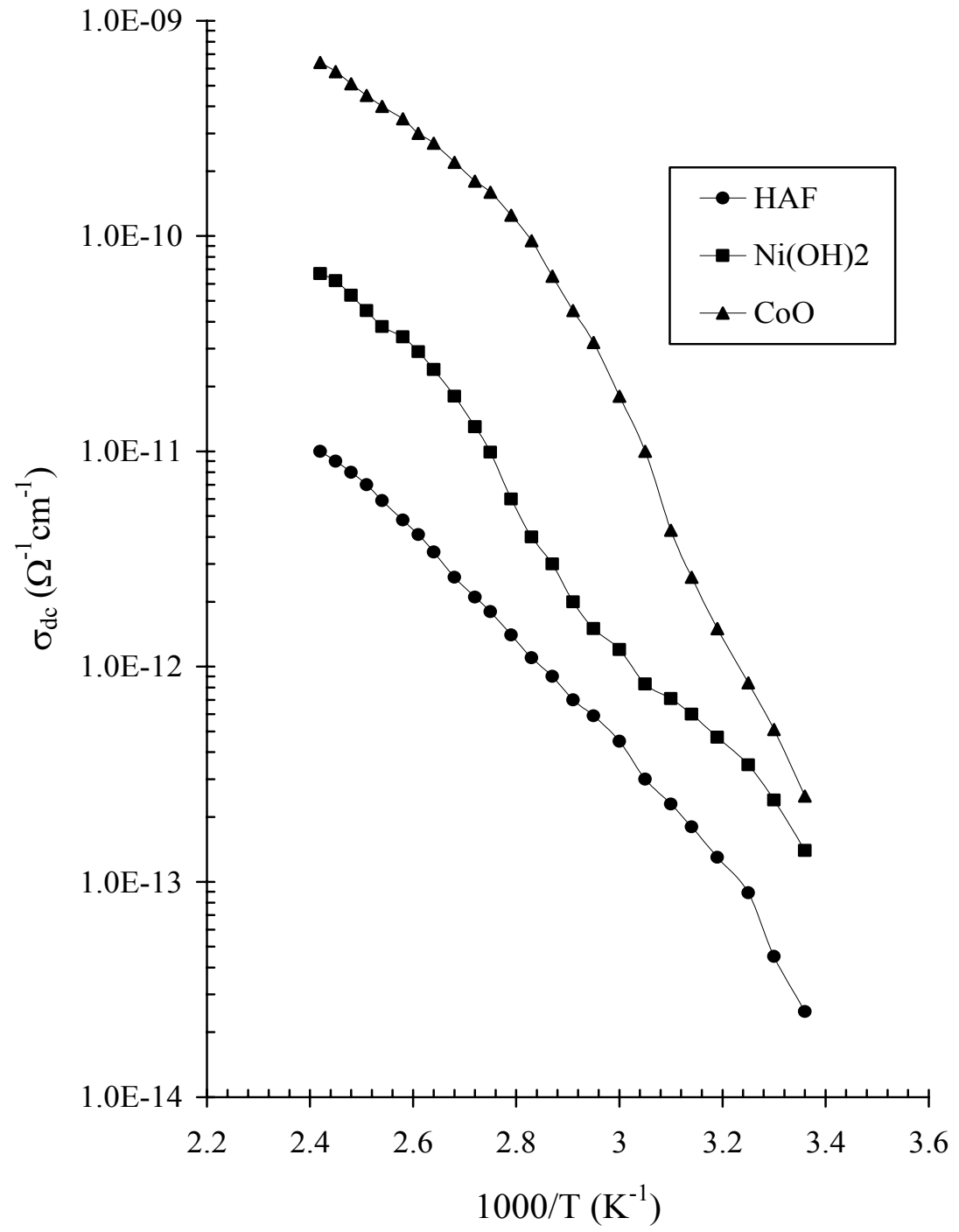

Fig. (5): The temperature dependence of the dc conductivity for composites containing $10 \mathrm{phr}$ of different fillers 


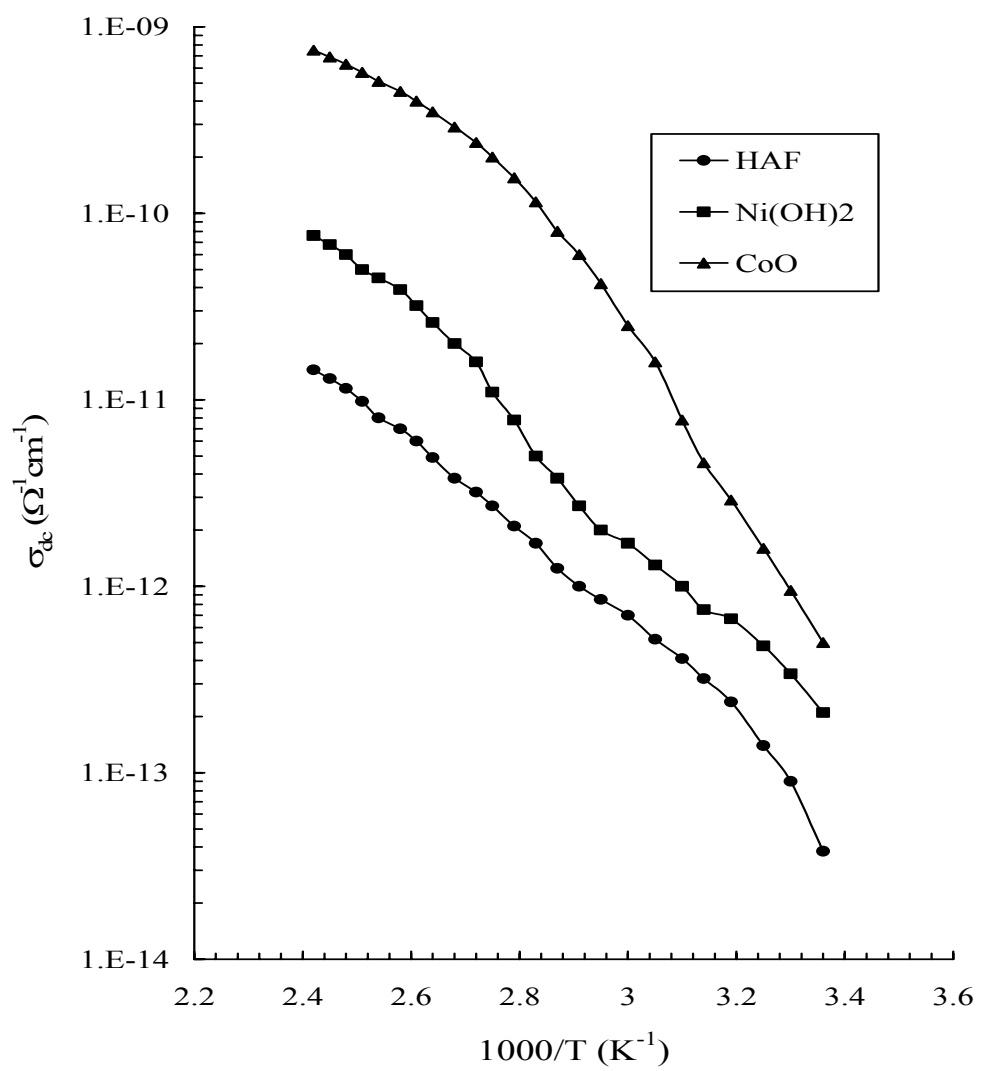

Fig. (6): The temperature dependence of the dc conductivity for composites containing $20 \mathrm{phr}$ of different fillers

Table (2): Values of the activation energy $\mathrm{E}(\mathrm{eV})$ calculated from the dc conductivity measurements.

\begin{tabular}{|c|c|c|c|c|}
\hline \multirow{2}{*}{ Sample } & \multirow{2}{*}{ phr } & \multicolumn{3}{|c|}{$\mathrm{E}(\mathrm{eV})$} \\
\cline { 3 - 5 } & & Region (1) & Region (2) & Region (3) \\
\hline \multirow{5}{*}{$\mathrm{CoO}$} & 1 & 0.88 & 1.96 & 0.35 \\
\cline { 2 - 5 } & 3 & 0.93 & 1.41 & 0.43 \\
\cline { 2 - 5 } & 5 & 0.91 & 1.20 & 0.39 \\
\cline { 2 - 5 } & 10 & 0.89 & 0.99 & 0.38 \\
\cline { 2 - 5 } & 20 & 0.81 & 0.68 & 0.41 \\
\hline \multirow{5}{*}{$\mathrm{Ni}(\mathrm{OH})_{2}$} & 1 & 0.5 & 1.5 & 0.57 \\
\cline { 2 - 5 } & 3 & 0.47 & 1.15 & 0.51 \\
\cline { 2 - 5 } & 5 & 0.46 & 0.95 & 0.46 \\
\cline { 2 - 5 } & 10 & 0.43 & 0.86 & 0.45 \\
\cline { 2 - 5 } & 20 & 0.37 & 0.79 & 0.34 \\
\hline
\end{tabular}


The frequency dependence of the dielectric constant and dielectric loss:

The frequency dependence of the dielectric constant $\varepsilon^{\prime}$ and dielectric loss $\varepsilon^{\prime \prime}$ of SBR-NBR interlinked systems loaded with both $\mathrm{CoO}$ and $\mathrm{Ni}(\mathrm{OH})_{2}$ at room temperature is shown in Figures (7-10), respectively. At room temperature $(300 \mathrm{~K})$ the dielectric constant has the values of 12.6 and 17 at 100 $\mathrm{Hz}$ for $\mathrm{Ni}(\mathrm{OH})_{2}$ and $\mathrm{CoO}$ loading of $20 \mathrm{phr}$, respectively, and 10.3 and 12.4 at $0.1 \mathrm{MHz}$. So, the contribution of $\mathrm{CoO}$ to the dielectric constant is relatively greater than that of $\mathrm{Ni}(\mathrm{OH})_{2}$. The graphs for all $\mathrm{Ni}(\mathrm{OH})_{2}$ and $\mathrm{CoO}$ loading [Figures (7) and (9)] show that $\varepsilon^{\prime}$ decreases linearly with $\log (\mathrm{f})$ in the frequency range of $100 \mathrm{~Hz}$ to $1 \mathrm{kHz}$ and remains at an almost constant value at higher frequencies. The plot of $\varepsilon^{\prime \prime}$ versus $\log (\mathrm{f})$ [Figures (8) and (10)] is decreasing almost linearly in the frequency range $100 \mathrm{~Hz}$ to $1 \mathrm{kHz}$ with different slopes $\left(=\frac{\Delta \varepsilon "}{\Delta \log f}\right)$ for the different types and concentrations of fillers.

In general, four possible factors may contribute to the low frequency dispersion that characterizes the frequency dependence of the dielectric constant of the interlinked systems NBR-SBR loaded with $\mathrm{CoO}$ and $\mathrm{Ni}(\mathrm{OH})_{2}[19]$.

\section{1) The effect of the electrode interface:}

Generally, there is an apparent increase in the dielectric constant at low frequencies [5]. Because no difference has been detected in the dielectric constant by applying different bias voltage, the contribution of this effect can be ignored.

\section{2) The effect of de conductivity:}

In principle, transport of charge in polymers takes place under the influence of an external electric field, even for a good insulator. The polymers have a bulk resistance that contributes to the measured dielectric properties, as it behaves as if it was connected in parallel with the sample capacitance. Unlike the resistive component due to the dipolar relaxation, [or the frequency dependent hopping conductivity $\sigma(\omega)$ ], the resistance due to this source is independent of frequency. This dc conductivity contributes only to the dielectric loss which becomes infinite at zero frequency and unimportant at very high frequency $[20,21]$.

\section{3) The dipole - orientation relaxation process:}

This process normally involves a rapid increase in the dielectric constant and a dielectric loss peak as the frequency, $\mathrm{f}$, is reduced. In the case of relatively $\mathrm{Ni}(\mathrm{OH})_{2}$ and $\mathrm{CoO}$ high loading $>10 \mathrm{phr}, \varepsilon^{\prime}$ increases as $\mathrm{f}$ goes to zero, which suggests a possible low- frequency dielectric relaxation, but there is no sign of a corresponding loss peak (Figs (8) and (10)). Therefore, it is difficult to ascribe the low frequency dispersion to a simple orientation relaxation process. 


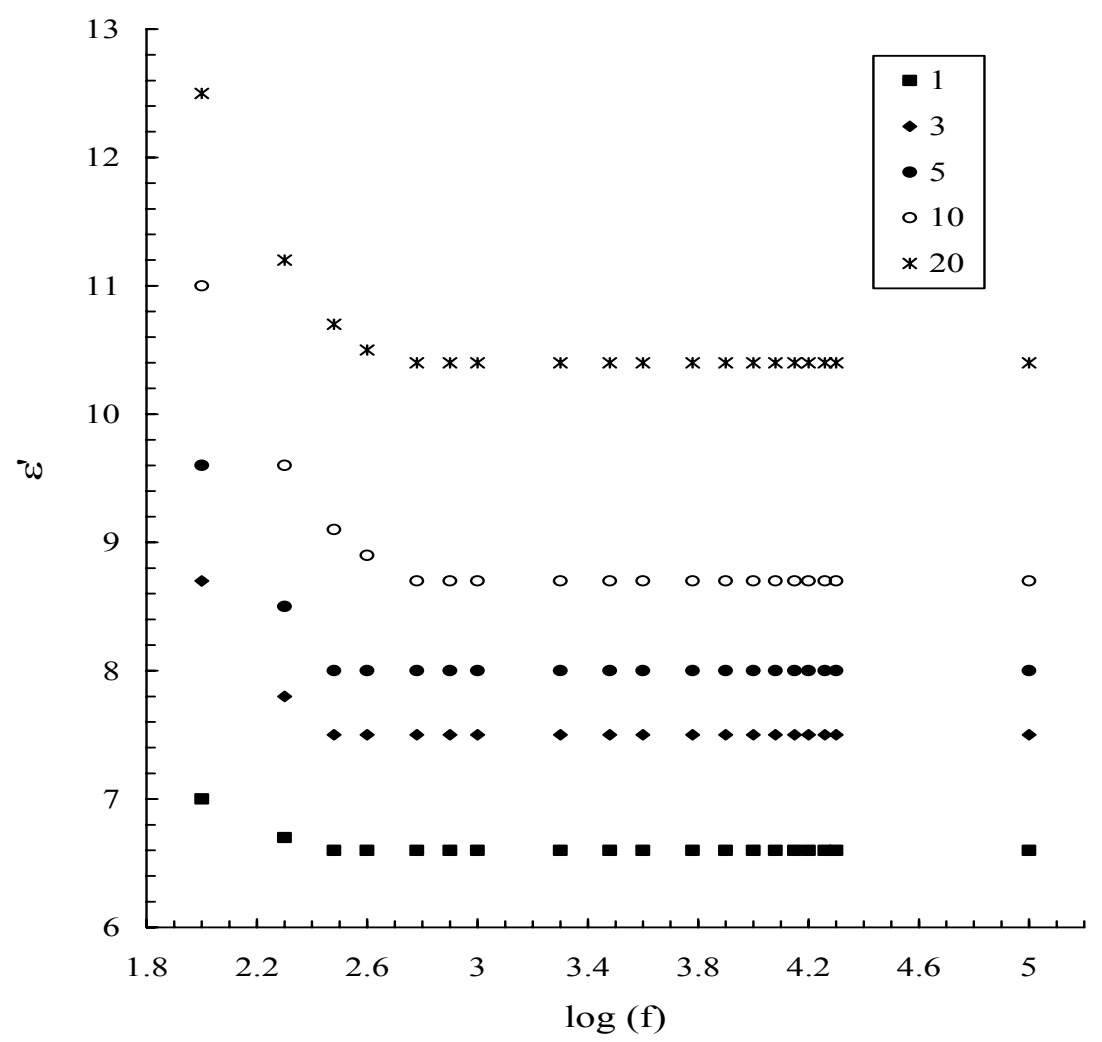

Fig. (7): The temperature dependence of the dielectric constant on frequency for composites containing different concentrations of $\mathrm{Ni}(\mathrm{OH})_{2}$.

\section{4) The effect of charge carriers:}

Charge carriers not only enable dc conduction but also make a contribution to the dielectric polarization [22]. The dielectric effects of free charge carriers, such as electrons, only become significant at frequencies of the order of the reciprocal collision time, which falls in the $10-100 \mathrm{GHz}$ range.

In the frequency range used in this work, free carriers effect is negligible and only localized charge carriers, which are ions, may contribute to the dielectric polarization. Charge carriers hopping movements between filler aggregates or particles are responsible for the conductivity. Although the low frequency dielectric behavior may well be ascribable to a hierarchy of barriers to the carrier diffusion, the observed dispersion can also be explained without assuming any particular type of barrier [22]. For a diffusive transport mechanism, it can be shown [24] that the complex dielectric constant obeys the relationship 


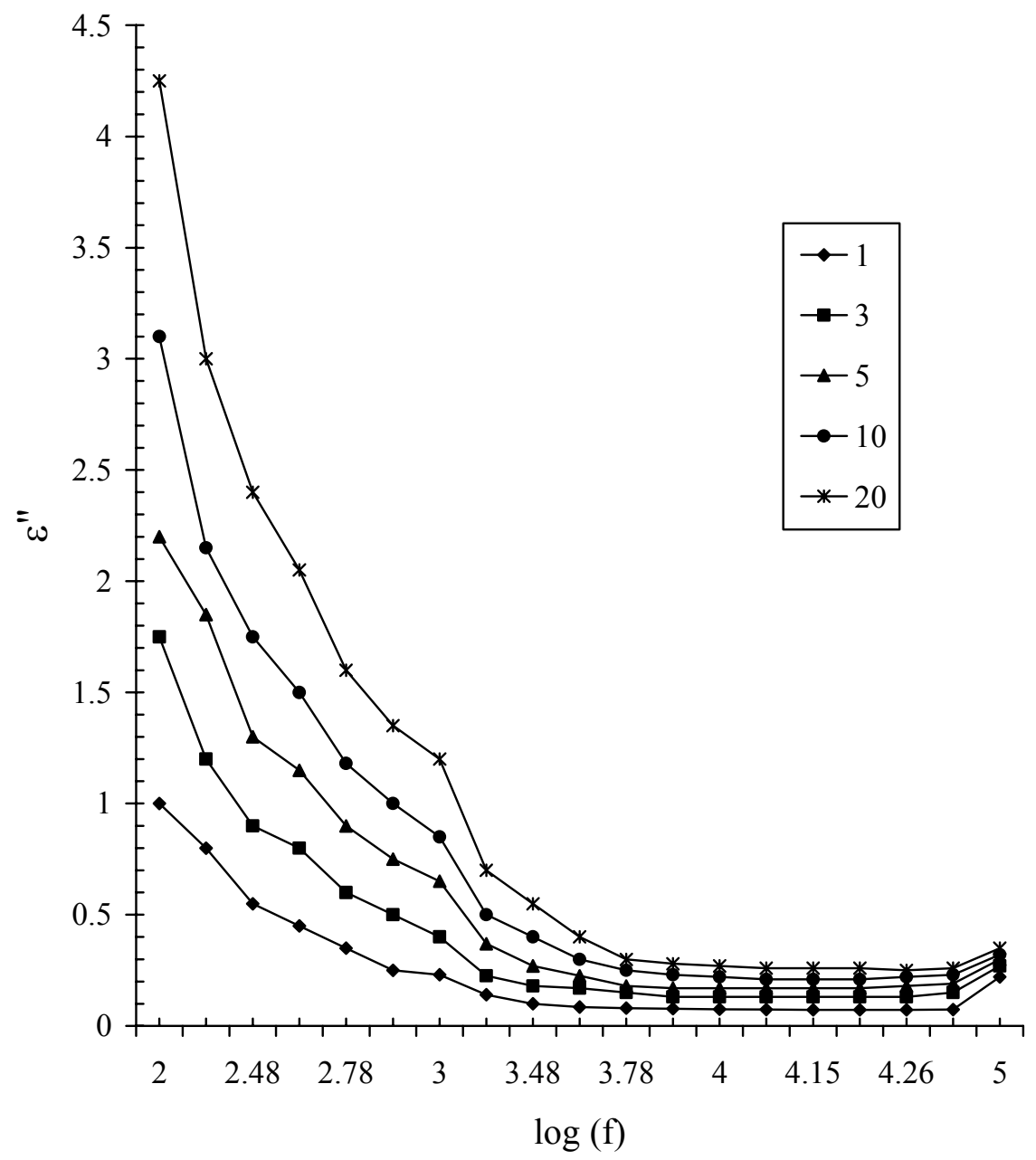

Fig. (8): The temperature dependence of the dielectric loss on frequency for composites containing different concentrations of $\mathrm{Ni}(\mathrm{OH})_{2}$.

$$
\varepsilon(\omega) \propto(1-i) \omega^{-1 / 2}
$$

Equation (7) has two important applications: (1) The real and imaginary parts are equal and there is no sign of any loss peak and (2) The real and imaginary parts increase indefinitely as the frequency is lowered. It can be seen from Figures (7-10) that the experimental data at $300 \mathrm{~K}$ obey these requirements quite well for all studied samples below $1 \mathrm{kHz}$. These results provide strong evidence that the low frequency dispersion of NBR-SBR loaded interlinked 
system arises mainly from the localized charge carrier conduction, which is characterized by a diffusion ion transport mechanism. The slopes of both the log $\left(\varepsilon^{\prime}\right)$ and $\log \left(\varepsilon^{\prime \prime}\right)$ versus $\log (f)$ at low frequencies are tabulated in Table (3).

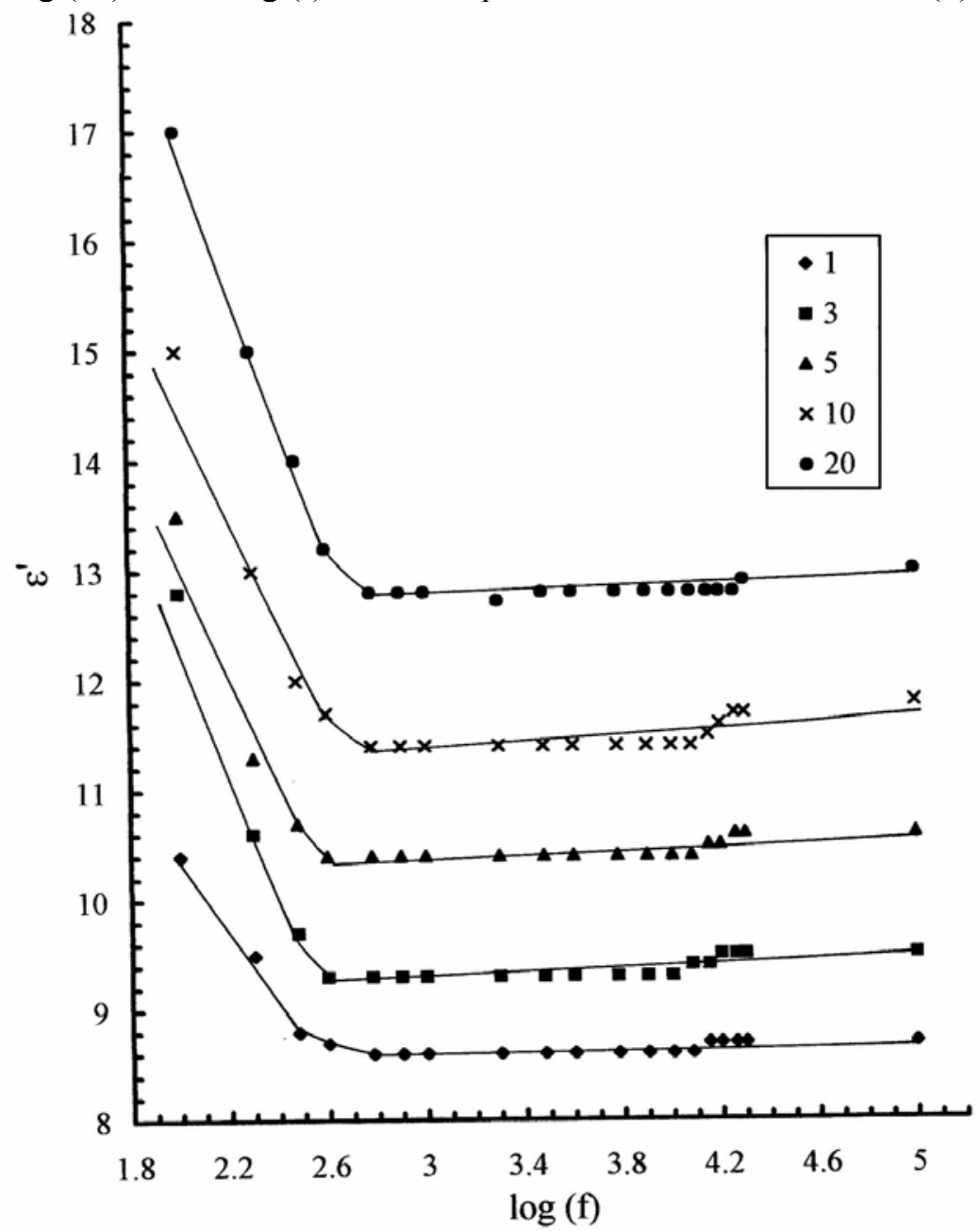

Fig. (9): The dependence of dielectric constant on frequency for composites containing different concentrations of $\mathrm{CoO}$.

\section{The ac conductivity:}

In such composites with an appreciable separation gap between filler particles, there is a certain resistance $R_{c}$ to the passage of electrons across the gap, which depends on temperature. The gap or junction has a capacitance $\mathrm{C}_{\mathrm{c}}$. An equivalent circuit representation of this system is shown in Figure (11). 


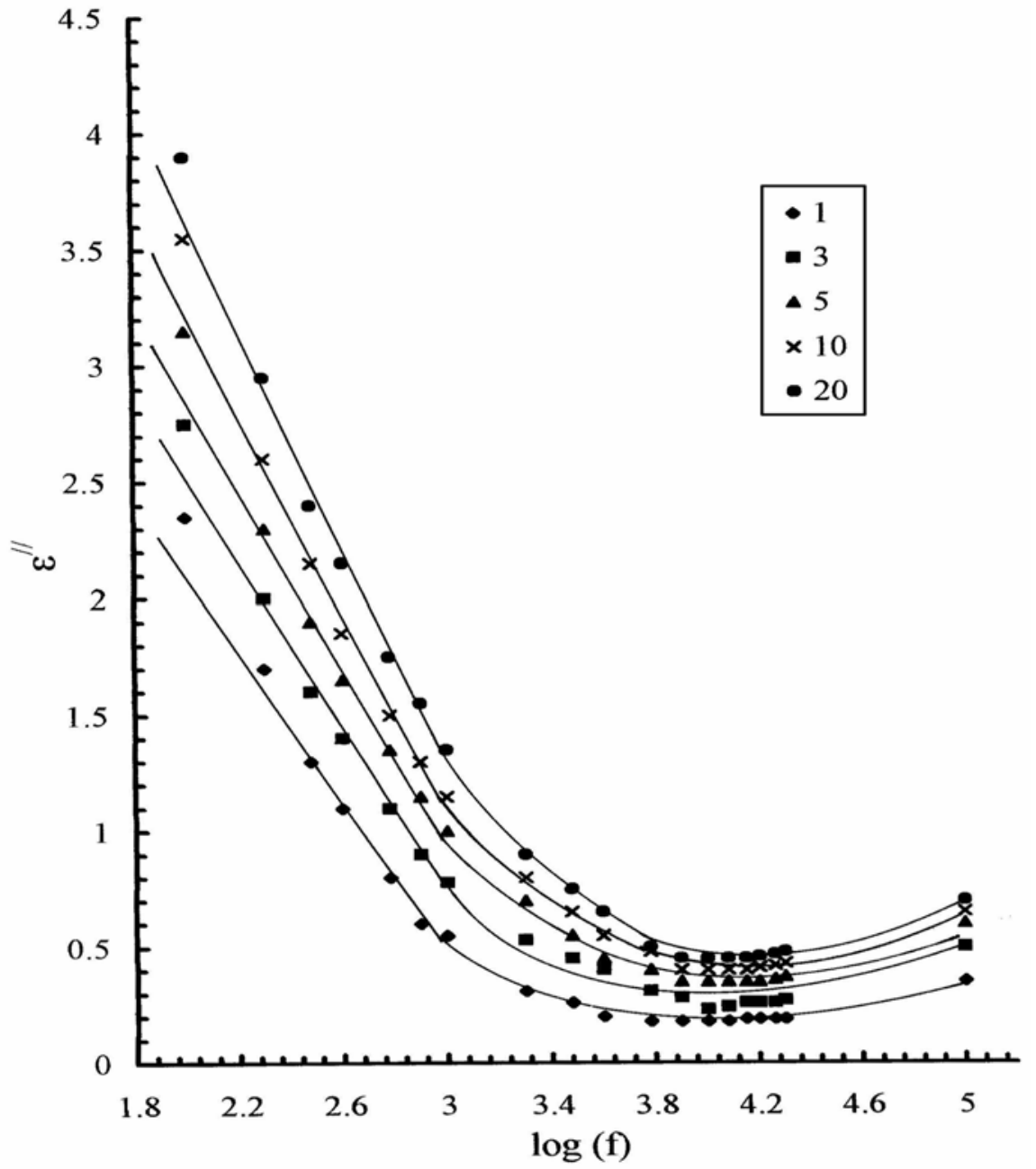

Fig. (10): The dependence of the dielectric loss on frequency for composites containing different concentrations of $\mathrm{CoO}$.

Table (3): The slopes values calculated from $\log \varepsilon^{\prime}$ and $\log \varepsilon^{\prime \prime}$ versus $\log \mathrm{f}$ at low frequencies (not presented here) for the two types of fillers.

\begin{tabular}{|c|c|c|c|c|c|c|c|c|c|c|}
\hline \multirow{2}{*}{ Slopes } & \multicolumn{6}{|c|}{ phr of CoO } & \multicolumn{5}{c|}{ phr of Ni(OH) } \\
\cline { 2 - 11 } & 1 & 3 & 5 & 10 & 20 & 1 & 3 & 5 & 10 & 20 \\
\hline$\frac{\Delta \varepsilon^{\prime}}{\Delta \log \mathrm{f}}$ & 0.14 & 0.20 & 0.16 & 0.17 & 0.19 & 0.07 & 0.10 & 0.11 & 0.12 & 0.12 \\
\hline$\frac{\Delta \varepsilon^{\prime \prime}}{\Delta \log \mathrm{f}}$ & 0.68 & 0.55 & 0.51 & 0.50 & 0.49 & 2.3 & 1.6 & 1.5 & 1.3 & 1.3 \\
\hline
\end{tabular}




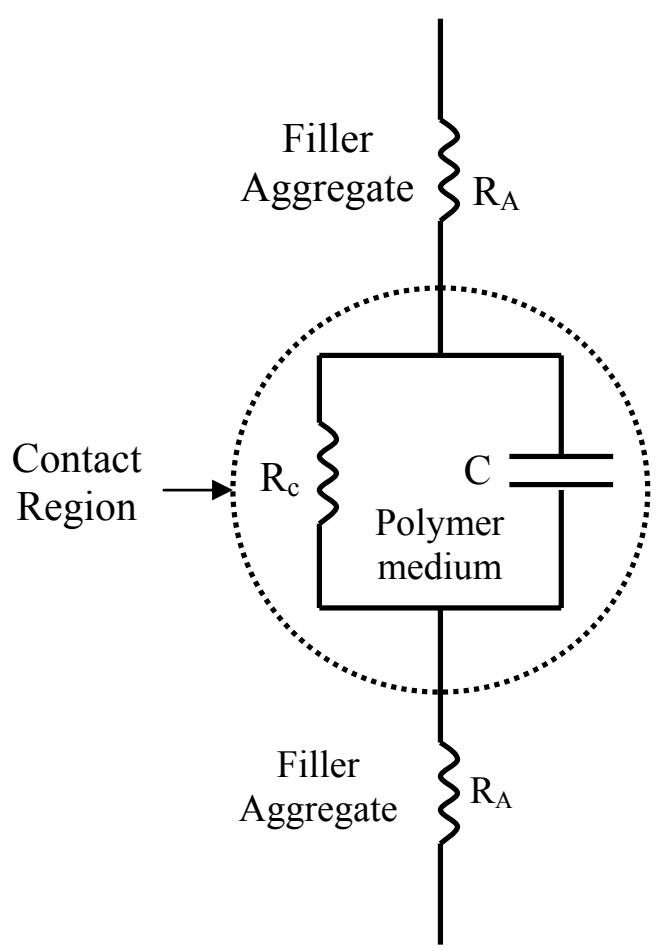

Fig. (11): Equivalent resistor- capacitor circuit in the contact region of filler aggregate.

As Kawamoto points out [23], at low frequency, the current flows through the contact resistance since it is blocked at the contact capacitance. The net resistance of the aggregate in series with the contact region is $\left(\mathrm{R}_{\mathrm{c}}+\mathrm{R}_{\mathrm{A}}\right)$ (where $R_{A}$ is the bulk resistance of the aggregate). At high frequencies, the impedance of the contact capacitance is much lower than the contact resistance, and the current flows through the contact capacitance. Furthermore, since the capacitor's impedance is much lower than the aggregate resistance, the net resistance at high frequency is equal to $\mathrm{R}_{\mathrm{A}}$, which is lower than the net resistance $\left(R_{c}+R_{A}\right)$ for the low frequency". Thus, the conductivity of a specimen starts to rise from its dc value $\left(\sigma_{c}\right)$ at a characteristic frequency as shown in Figures (12) and (13) for both types of filler loading, and a change in slope is detected at certain value $\left(\sigma_{\mathrm{H}}\right)$ and will be levels off at very high frequency $(>10 \mathrm{MHz})[5]$ which is that of filler particles alone and not detected in our case. 


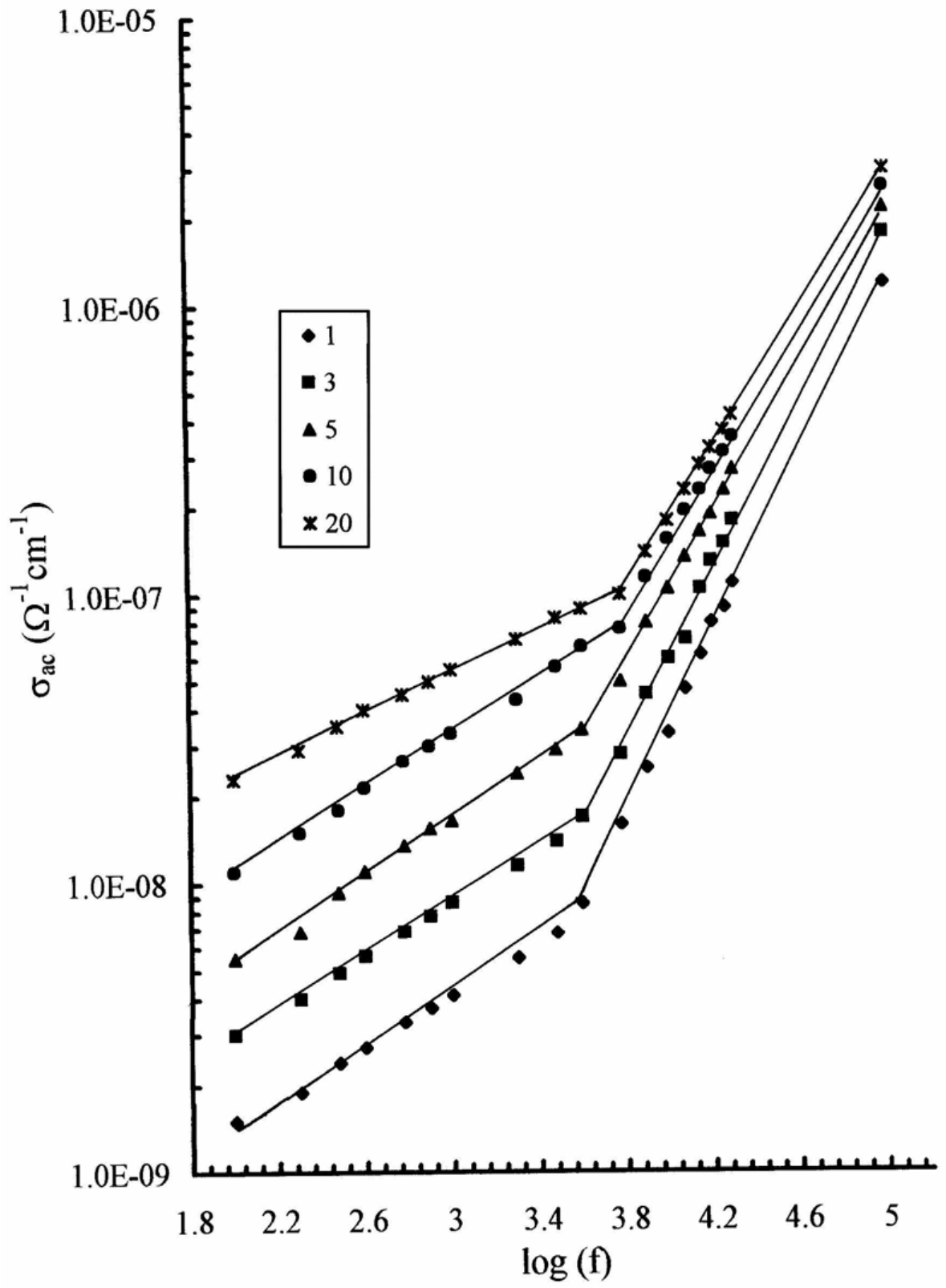

Fig. (12): The dependence of the ac conductivity on frequency for composites containing different concentrations of $\mathrm{Ni}(\mathrm{OH}) 2$. 


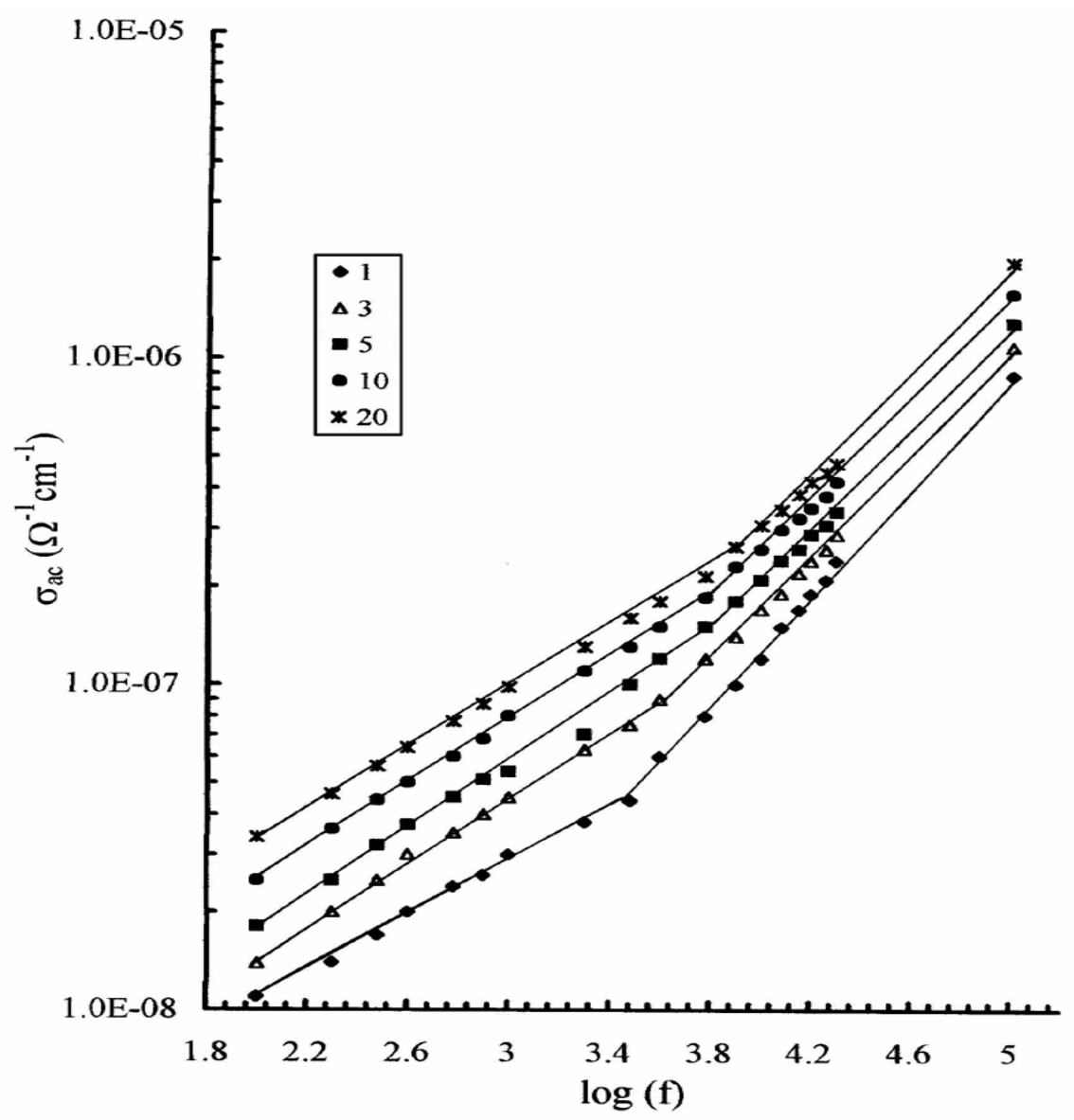

Fig. (13): The dependence of the ac conductivity on frequency for composites containing different concentrations of $\mathrm{CoO}$.

Citing Kawamoto again, as the loading density is increased, the aggregates are more tightly packed and pressed against each other. This results in the reduction of both the separation gap and internal contact resistance $R_{c}$. Thus the net resistance $\left(R_{c}+R_{A}\right)$ decreases with increasing loading level. When the contact resistance becomes much lower than the filler aggregate resistance, the net resistance is equal to $\mathrm{R}_{\mathrm{A}}$ at both low and high frequencies. Therefore, no frequency dependence exists at high loading level $(50 \mathrm{phr}$ as detected before for the case of HAF black). Moreover, the critical frequency $f_{c}$ is highly affected by both the type and the concentration of the used filler as shown in Table (4). The values of $\mathrm{f}_{\mathrm{c}}$ assumes lower values at the same loading for $\mathrm{CoO}$ filler than for $\mathrm{Ni}$ $(\mathrm{OH})_{2}$. Meanwhile, it is shifted to higher values upon increasing the filler loading for each type. 
Table (4): The observed critical frequency as function of both $\mathrm{CoO}$ and $\mathrm{Ni}(\mathrm{OH})_{2}$ content.

\begin{tabular}{|c|c|c|c|c|c|c|c|c|c|c|}
\hline & \multicolumn{5}{|c|}{ COO } & \multicolumn{6}{c|}{ Ni(OH) } \\
\hline Phr & 1 & 3 & 5 & 10 & 20 & 1 & 3 & 5 & 10 & 20 \\
\hline $\mathrm{f}_{\mathrm{c}}(\mathrm{Hz})$ & 2930 & 3690 & 4140 & 5110 & 6165 & 3980 & 4300 & 4730 & 6300 & 7645 \\
\hline
\end{tabular}

\section{Conclusion:}

From this work it is concluded that the addition of $\mathrm{CoO}$ to an SBRNBR interlinked matrix increases the electrical conductivity more than $\mathrm{Ni}(\mathrm{OH})_{2}$ do and any one of these two fillers increases the conductivity more than HAF black. Also white fillers decrease the activation energy. The low frequency dispersion of SBR-NBR loaded interlinked system arises mainly from the localized charge carrier conduction, which is characterized by a diffusion ion transport mechanism. White fillers decrease the dielectric constant in the frequency range $100 \mathrm{~Hz}$ to $1 \mathrm{kHz}$ and also decrease the dielectric loss in the frequency range $100 \mathrm{~Hz}$ to $5 \mathrm{kHz}$.

\section{References:}

1. Ryo Oono, J. Appl. Polym. Sci., 21,1743 (1977).

2. Hassan H.H, Ghani A.A., Eatah A.E. and Hashem A.A, Angew. Makromol. Chem., 115, 39 (1991).

3. Ghani A.A., Eatah A.E., Hashem A.A. and Hassan H.H., angew. Makromol. Chem., 129, 1-9 (1985).

4. Seanor D.A. "Electrical Properties of Polymers" Academic Press, New York 68 (1982).

5. Blythe A.R. "Electrical Properties of Polymers", Cambridge Univ. Press, London 100 (1977)

6. Sichel E.K., "Carbon Black Polymer Composites: The Physics of Electrically Conducting Compounds" Marcel Dekker, New York, 50 (1982)

7. Norman R.H., "Conductive Rubber and Plastics", Appl. Sci., Pub. LTD London 75 (1970)

8. Abdel-Bary E.M., Amin M. and Hassan H.H., J. Polym. Sci., Polym. Chem. Ed., 17, 2163 (1979)

9. Chang R.J. and Gent A.N., J. Polym. Sci., Polym. Phys. Ed., 19,1619, (1981).

10. Bhowmick A.K. and Gent A.N., J. Rubber. Chem., Tech. 57(26) 217 (1982).

11. Battacharya T. and De SK, J. Polym. Sci., Polym. Phys. Ed., 33, 7, 2183 (1995). 
12. Fraser W.A., Ancker F.H., DiBenedetto A.T. and Elbirli B., Poly Comp, 4, 238 (1983).

13. Bowyer W.H. and Bader M.G., J. Matt. Sci., 7, 1315 (1972).

14. Agarwal B.D and Bansal R.K, Fibre Sci., Tech., 12, 149 (1979).

15. Nasr G.M, Osman H.M, Abu-Abdeen M. and Aboud A.I, Poly. Test, 18, 7, 483 (1999).

16. Suenasu H., J. Matter Sci. 19, 2, 574 (1984).

17. Sichel E.K, Gittleman J.I. and Sherg P., "Carbon Black-Polymer Composites" Sichel E.K., Ed, Marcel Dekker, New York, 45 (1982).

18. Azaroff L.V. and Brophy J.J. "Electronic Processes in Materials" McGrawHill, New York 33 (1963).

19. Fanggao C., Saunders G.A, Lambson E.F., Hampton R.N, Carini G, Marco G. di and Lanza M, J. Ploym. Sci., Polym. Phys., 34, 425 (1996)

20. Hill N.E, Vaughan W.E, Price A.M, and Davies M, "Dielectric properties and Molecular behavior", van Nostirand Reinhold Company, London, 203 (1969)

21. Boyd R.H, "Methods of Experimental Physics", R.A.Fava (ed.), 16c, 379 (1980)

22. Jonscher A.K., "Dielectric Relaxation in Solids", Chelsea. Dielectric Press London (1983).

23. Kawamoto H., "Carbon Black - Polymer composites", E.K. Siechel, Ed., Marcel Dekker, New York Ch. 5 (1982) 